\title{
Effect of Estradiol as a Continuous Variable on Breast Cancer Survival by Menopausal Status: A Cohort Study in China
}

\section{Junxian Li}

Tianjin Tumor Hospital

Chenyang Li

Tianjin Tumor Hospital

Ziwei Feng

Tianjin Tumor Hospital

Luyang Liu

Tianjin Tumor Hospital

Liwen Zhang

Tianjin Tumor Hospital

\section{Wenjuan Kang}

Tianjin Tumor Hospital

Ya Liu

Tianjin Tumor Hospital

\section{Baoshan Ma}

Tianjin Tumor Hospital

\section{Haixin Li}

Tianjin Tumor Hospital

\section{Yubei Huang}

Tianjin Tumor Hospital

Hong Zheng

Tianjin Tumor Hospital

\section{Fangfang Song}

Tianjin Tumor Hospital

Fengju Song ( $\square$ songfengju@163.com )

Tianjin Tumor Hospital https://orcid.org/0000-0003-1542-0828

\section{Kexin Chen}

Tianjin Tumor Hospital 
Keywords: breast cancer, estradiol, survival, menopause status, ER status

Posted Date: September 27th, 2021

DOI: https://doi.org/10.21203/rs.3.rs-923834/v1

License: (c) (1) This work is licensed under a Creative Commons Attribution 4.0 International License. Read Full License 


\section{Abstract}

\section{Background}

High levels of circulating estradiol (E2) are associated with increased risk of breast cancer, whereas its relationship with breast cancer prognosis is still unclear. We studied the effect of E2 concentration on breast cancer survival among pre- menopausal and post- menopausal patients in China.

\section{Methods}

We evaluated this association among 8766 breast cancer cases diagnosed between 2005 and 2017 from the Tianjin Breast Cancer Cases Cohort. Levels of serum E2 were measured in pre-menopausal and postmenopausal women. Multivariable-adjusted Cox proportional hazards models were used to estimate hazard ratios (HR) and $95 \%$ confidence intervals $(95 \% \mathrm{Cl})$ between quartile of E2 levels and overall survival (OS) and progression-free survival (PFS) of breast cancer. The penalized spline was then used to test for non-linear relationships between E2 (continuous variable) and survival endpoints.

Results

A total of 612 deaths and 982 progressions occurred over follow-up through 2017. Compared to women in the quartile 3, the highest quartile of E2 was associated with reduced risk of both PFS in premenopausal women (HR=1.79, 95\% $\mathrm{Cl}$ : 1.17-2.75, $P=0.008)$ and $\mathrm{OS}$ in post-menopausal women (HR=1.35, 95\% Cl: 1.04-1.74, $P=0.023)$. OS and PFS in pre-menopausal women exhibited a nonlinear relation ("L-shaped" and "U-shaped", respectively) with E2 levels. However, there was a linear relationship in post-menopausal women, among whom increasing E2 was associated with escalating risks of death and progression. Moreover, patients with estrogen receptor-negative (ER-negative) breast cancer showed a "U-shaped" relationship with OS and PFS in pre-menopausal women.

\section{Conclusions}

Pre-menopausal breast cancer patients have a plateau stage of prognosis at the intermediate concentrations of E2, whereas post-menopausal patients have no apparent threshold, and ER status may have an impact on this relationship.

\section{Introduction}

Breast cancer is the sixth leading cause of death in China[1,2] and the fifth leading cause of death worldwide[3]. Most breast tumors are estrogen-dependent, and medications to inhibit or block estrogen are the mainstay of treatment for women with ER-positive breast cancer[4]. As one of the most biologically active estrogens, estradiol (E2) behaves differently in different menopausal status[5]. In premenopausal women, estradiol is mainly produced by granulosa cells of follicles, which fluctuate during the female menstrual cycle[6]. The serum concentrations of E2 are subject to slight fluctuations after menopause[7]. 
There is an increasing interest in the role of E2 levels for breast cancer initiation[8, 9], progression, and prognosis. Several lines of epidemiologic evidence have indicated a role of pre-menopausal E2 in breast cancer etiology $[9,10]$. Among post-menopausal women, a large-scale prospective cohort has firmly established high E2 levels as being significantly associated with increased breast cancer risk[11]. With regard to prognosis, few studies have explored the relationship between E2 concentrations and prognosis among pre-menopausal women newly diagnosed with breast cancer. In post-menopausal patients, studies to date have offered conflicting insights on the association between E2 levels and clinical outcomes of breast cancer ${ }^{[12-14]}$. There is likewise little evidence for a dose-response relationship between serum E2 and prognosis of breast cancer in pre-menopausal and post-menopausal patients.

Therefore, the present study aimed to investigate the association between preoperative E2 levels and breast cancer death, recurrence, and metastasis among Chinese pre-menopausal and post-menopausal patients.

\section{Methods}

\subsection{Study Population and Design}

The Tianjin Breast Cancer Cases Cohort (TBCCC) was launched in 2004 and last updated by the end of 2017 from Tianjin Medical University Cancer Institute and Hospital. TBCCC aimed to support studies on breast cancer survival, disease progression, quality of life in Chinese breast cancer patients, and strove to achieve precise medical care[15, 16]. Patients were diagnosed as breast cancer for the first time through clinical-pathological examination after admission to Tianjin Medical University Cancer Institute and Hospital. We collected the demographic and epidemiological data of patients through a structured questionnaire, and abstracted clinicopathological and therapeutic information from medical records, and attained vital status once a year by telephone. Moreover, hospital information system and Tianjin Cancer Death Registry System were used to confirm self-reported information of vital status, such as recurrence, metastasis, and death. This study was approved by the research ethics board of the Tianjin Medical University Cancer Institute and Hospital.

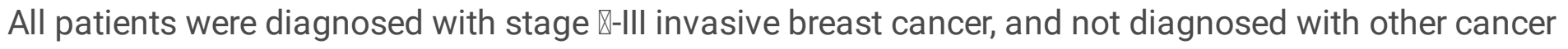
previously. All patients had written informed consent in TBCCC. The final analytic sample included 8766 patients who donated a blood sample and had complete data on preoperative E2 levels.

\subsection{Measures of E2 levels and Covariates}

Fasting, early follicular blood samples were obtained from each patient at baseline within 5 days after menstruation cessation. Circulating E2 measurements were completed by using Mindray CL-6000i chemiluminescence analyzer detection system (China). Blood samples were detected within 24 hours since the completion of collection. 
The questionnaire was used to obtain baseline information on age at diagnosis and body mass index (BMI). The hospital information system (HIS) electronic medical record was used to obtain information on histological grade, pT, pN, stage, ER, progesterone receptor (PR), human epidermal growth factor receptor-2 (HER2), and treatment regimen. BMI was calculated as kilograms per square meter of height $\left(\mathrm{kg} / \mathrm{m}^{2}\right)$. Underweight was defined as BMI $18.5 \mathrm{~kg} / \mathrm{m}^{2}$, normal as BMI of $18.5-23.9$, overweight as BMI of 24-27.9, and obesity as BMI $\geq 28 \mathrm{~kg} / \mathrm{m}^{2}$. The ER, PR, and HER2 expressions were detected by the immunohistochemistry (IHC) method. The tumor was considered ER positive or PR positive if there were $\geq 1 \%$ nuclear-stained malignant cells. For HER2, the stained tumor cell nuclear and nuclear staining intensity was semi-quantitatively evaluated using a grade between 0 and $3+$. Results of $0,1+$, or $2+/ F I S H$ negative were indicated as HER2 negative, whereas 2+ /FISH positive or $3+$ were positive[17].

\subsection{Statistical Analysis}

Categorical variables are presented as frequencies ( $n$ ) and percentages (\%) and continuous variables as mean (SD) for normally distributed data or median (IQR) for non-normal data. Characteristics of the two different subgroups were compared using $\chi^{2}$ analysis, the t-test or Mann-Whitney test, as appropriate. OS was measured from time at diagnosis to death, regardless of cause, and PFS, to survival without evidence of relapse, progression, or death. Multivariable-adjusted Cox proportional hazards models were used to evaluate associations between serum E2 levels and mortality or disease progression risk. Models were adjusted for age at diagnosis, BMI, pT, pN, stage, histological grade, ER, PR, HER2 status, chemotherapy, radiotherapy, and endocrine treatment. The selection of the final model stratified by menopausal status (pre-menopause and post-menopause) was performed using a backward step downselection process. The penalized spline (P-spline) in the Cox model allows a nonlinear relationship of E2 levels with the logarithm (In hazard ratio [18]) of disease progression or mortality, estimated from the Cox regression model adjusted for significant covariates in univariable analysis. We used the dfmacox (degrees of freedom in multivariate additive Cox models) function in smoothHR to obtain the optimal number of degrees of freedom in the extended Cox-type additive multivariate analysis[19]. The lowest risk point was used as the reference value. Performance of E2 concentrations was plotted by ER status using hazard ratios (HR) and $95 \%$ confidence intervals $(\mathrm{Cl})$. Linearity and nonlinearity were inspected visually using Martingale residual plots and examined statistically using likelihood ratio tests[20]. The assumption of proportional hazards was examined by visual inspection of residuals plots on time and using the Schoenfeld residuals test. Statistical significance was set as $P<0.05$ in a two-tailed test. All statistical analyses were performed using R version 4.1.0 (R Foundation) and SAS 9.4 (SAS Institute Inc).

\section{Results}

\subsection{Baseline patient characteristics}

Patients' tumor characteristics and treatments by menopausal status are summarized in Table 1 , including 4207 pre-menopausal and 4559 post-menopausal women. Compared with pre-menopausal patients, post-menopausal patients had a lower median E2 concentration, an older diagnostic age (91.7\% 


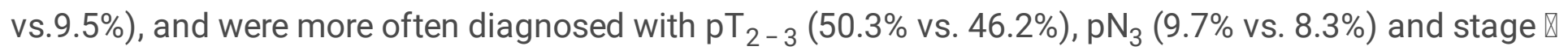
disease ( $15.9 \%$ vs. $14 \%)$. While pre-menopausal patients were more likely to have a significantly higher proportion of Grade $\otimes(11.8 \%$ vs. $8.4 \%)$ and ER-positive (69.8\% vs. $46.2 \%)$, PR-positive ( $72.3 \%$ vs. $59 \%)$ and HER2- tumors (90.8\% vs. $87.3 \%$ ). In addition, pre-menopausal patients were more likely to receive adjuvant chemotherapy, radiotherapy, and endocrine treatment compared with post-menopausal women. During a median follow-up of 65 months ( $95 \%$ Cl: 63-67 months), 982 (385 in pre- menopausal and 597 in post-menopausal) progressions, including 612 (203 in pre- menopausal and 409 in post-menopausal) deaths, occurred. The proportion of patients' characteristics was significantly distinct between premenopausal and post-menopausal cases $(P<0.001)$ and the study population was then stratified according to menopausal status. 
Table 1

Characteristics of breast cancer patients by menopausal status

\section{Characteristics}

\section{Menopausal status}

Pre-menopausal

No. (\%)

\section{Post-menopausal}

No. (\%)

Estradiol

median (IQR)

$82.9(38.8-149.9)$

$7.5(5-13.9)$

Age of diagnosis (years)

$\leq 50$

$3807(90.5)$

$379(8.3)$

$₫ 50$

$400(9.5)$

$4180(91.7)$

Body mass index $\left(\mathrm{kg} / \mathrm{m}^{2}\right)$

$<18.5$

$89(2.1)$

$102(2.2)$

$18.5-23.9$

$1730(41.7)$

1962 (43.1)

$24-27.9$

1524 (36.8)

1730 (38.0)

$\geq 28$

803 (19.4)

753 (16.6)

ER status

negative

1159 (30.3)

2214 (53.8)

positive

$2673(69.8)$

1904 (46.2)

PR status

negative

1061 (27.7)

$1768(41.0)$

positive

$2772(72.3)$

$2543(59.0)$

HER2 status

negative

$2396(90.8)$

2794 (87.3)

positive

$244(9.2)$

Abbreviations: IQR, inter-quartile range; ER, estrogen receptor; PR, progesterone receptor; HER-2, Human epidermal growth factor receptor-2.

Abbreviations: $\mathrm{HR}$, hazard ratio; $\mathrm{Cl}$, confidence interval; $\mathrm{BMI}$, body mass index; $\mathrm{ER}$, estrogen receptor; PR, progesterone receptor; HER2, human epidermal growth factor receptor-2.

Abbreviations: OS, Overall Survival; PFS, Progression Free Survival.

Abbreviations: ER, estrogen receptor; OS, Overall Survival; PFS, Progression Free Survival. 


\begin{tabular}{|c|c|c|}
\hline \multirow[t]{3}{*}{ Characteristics } & \multicolumn{2}{|c|}{ Menopausal status } \\
\hline & Pre-menopausal & Post-menopausal \\
\hline & No. (\%) & No. (\%) \\
\hline \multicolumn{3}{|c|}{ Histological grade } \\
\hline ૧ & $405(11.8)$ & $312(8.4)$ \\
\hline ૧ & $2415(70.6)$ & 2649 (71.3) \\
\hline$\square$ & $603(17.6)$ & $752(20.3)$ \\
\hline \multicolumn{3}{|l|}{ pT } \\
\hline $\mathrm{pT}_{0-1}$ & 2107 (53.9) & 2179 (49.7) \\
\hline $\mathrm{pT}_{2}$ & $1602(41.0)$ & $1997(45.5)$ \\
\hline $\mathrm{pT}_{3}$ & $203(5.2)$ & $210(4.8)$ \\
\hline \multicolumn{3}{|l|}{$\mathrm{pN}$} \\
\hline $\mathrm{pN}_{1}$ & 3459 (82.2) & $3648(80.0)$ \\
\hline $\mathrm{pN}_{2}$ & $400(9.5)$ & $471(10.3)$ \\
\hline $\mathrm{pN}_{3}$ & $348(8.3)$ & $440(9.7)$ \\
\hline \multicolumn{3}{|l|}{ Stage } \\
\hline ૧ & $1779(45.1)$ & $1714(39.0)$ \\
\hline ૧ & $1616(41.0)$ & $1984(45.1)$ \\
\hline ૧ & $551(14.0)$ & $699(15.9)$ \\
\hline \multicolumn{3}{|l|}{ Chemotherapy } \\
\hline No & $840(20.0)$ & $1140(25.0)$ \\
\hline Done & $3367(80.0)$ & 3419 (75.0) \\
\hline Radiotherapy & & \\
\hline
\end{tabular}

Abbreviations: IQR, inter-quartile range; ER, estrogen receptor; PR, progesterone receptor; HER-2, Human epidermal growth factor receptor-2.

Abbreviations: $\mathrm{HR}$, hazard ratio; $\mathrm{Cl}$, confidence interval; $\mathrm{BMI}$, body mass index; $\mathrm{ER}$, estrogen receptor; PR, progesterone receptor; HER2, human epidermal growth factor receptor-2.

Abbreviations: OS, Overall Survival; PFS, Progression Free Survival.

Abbreviations: ER, estrogen receptor; OS, Overall Survival; PFS, Progression Free Survival. 


\begin{tabular}{|c|c|c|}
\hline \multirow[t]{3}{*}{ Characteristics } & \multicolumn{2}{|c|}{ Menopausal status } \\
\hline & Pre-menopausal & Post-menopausal \\
\hline & No. (\%) & No. (\%) \\
\hline No & $3208(76.3)$ & 3675 (80.6) \\
\hline Done & $999(23.8)$ & $884(19.4)$ \\
\hline \multicolumn{3}{|c|}{ Endocrine treatment } \\
\hline No & $3243(77.1)$ & $3672(80.5)$ \\
\hline Done & $964(22.9)$ & $887(19.5)$ \\
\hline \multicolumn{3}{|l|}{ Progression } \\
\hline No & $3822(90.9)$ & 3962 (86.9) \\
\hline Yes & $385(9.2)$ & $597(13.1)$ \\
\hline \multicolumn{3}{|l|}{ Death } \\
\hline No & $4004(95.2)$ & $4150(91.0)$ \\
\hline Yes & $203(4.8)$ & 409 (9.0) \\
\hline \multicolumn{3}{|c|}{$\begin{array}{l}\text { Abbreviations: IQR, inter-quartile range; ER, estrogen receptor; PR, progesterone receptor; HER-2, } \\
\text { Human epidermal growth factor receptor- } 2 \text {. }\end{array}$} \\
\hline \multicolumn{3}{|c|}{$\begin{array}{l}\text { Abbreviations: } \mathrm{HR} \text {, hazard ratio; } \mathrm{Cl} \text {, confidence interval; } \mathrm{BMI} \text {, body mass index; } \mathrm{ER} \text {, estrogen receptor; } \\
\text { PR, progesterone receptor; } \mathrm{HER} 2 \text {, human epidermal growth factor receptor- } 2 \text {. }\end{array}$} \\
\hline \multicolumn{3}{|c|}{ Abbreviations: OS, Overall Survival; PFS, Progression Free Survival. } \\
\hline \multicolumn{3}{|c|}{ Abbreviations: ER, estrogen receptor; OS, Overall Survival; PFS, Progression Free Survival. } \\
\hline
\end{tabular}

The association of the serum E2 levels with breast cancer survival, including OS and PFS, is presented in Fig. 1 according to menopausal status. The ranges of menopausal status-specific quartile groups of the E2 value were as follows: pre-menopause, quartile 1 (Q1): $\leq 38.83 \mathrm{ng} / \mathrm{L}$, quartile 2 (Q2): 38.84 to 82.94 $\mathrm{ng} / \mathrm{L}$, quartile 3 (Q3): 82.95 to $149.9 \mathrm{ng} / \mathrm{L}$ and quartile 4 (Q4): $>149.9 \mathrm{ng} / \mathrm{L}$ and post-menopause, quartile 1 (Q1): $\leq 5 \mathrm{ng} / \mathrm{L}$, quartile 2 (Q2): 5.1 to $7.49 \mathrm{ng} / \mathrm{L}$, quartile 3 (Q3): 7.50 to $13.94 \mathrm{ng} / \mathrm{L}$ and quartile 4 (Q4): $>13.94 \mathrm{ng} / \mathrm{L}$. Q3 was used as reference group in further analysis.

Figure 1A shows HRs $(95 \% \mathrm{Cl})$ for OS and PFS in pre-menopausal patients. Patients with $\mathrm{E} 2<82.95 \mathrm{ng} / \mathrm{L}$ or E2 > $142.9 \mathrm{ng} / \mathrm{L}$ had an increased hazard of OS with the references $(\mathrm{Q} 1: \mathrm{HR}=1.42,95 \% \mathrm{Cl}$ : 0.76-2.67; Q2: $\mathrm{HR}=1.90,95 \% \mathrm{Cl}: 1.02-3.54 ; \mathrm{Q} 4: \mathrm{HR}=1.50,95 \% \mathrm{Cl}: 0.78-2.89)$, the serum E2 quartile group 2 was at a greater risk of death than the other groups $(P=0.042)$; serum E2 quartile groups 2 and 4 had a 
significantly higher risk for progression than serum E2 quartile group 3 (Q2: $\mathrm{HR}=1.62,95 \% \mathrm{Cl}$ : $1.04-2.52$; Q4: $\mathrm{HR}=1.79,95 \% \mathrm{Cl}: 1.17-2.75)$.

Figure 1B shows HRs $(95 \% \mathrm{Cl})$ for OS and PFS in post-menopausal patients. The highest serum E2 level has significantly higher $\mathrm{HR}$ for death than the Q3 level $(\mathrm{HR}=1.35,95 \% \mathrm{Cl}: 1.04-1.74 ; P=0.023)$. The highest E2 levels had a non-significantly higher risk for progression (Q1: HR = 1.10, 95\% Cl: 0.89-1.37; Q2: $\mathrm{HR}=1.12,95 \% \mathrm{Cl}: 0.82-1.51 ; \mathrm{Q} 4: \mathrm{HR}=1.15,95 \% \mathrm{Cl}: 0.93-1.43)$.

\subsection{Dose-response relationship between E2 and breast cancer survival}

The dose-response relationships between E2 and death or progression were analyzed in patients before and after menopause, adjusting for the same confounding factors (Fig. 2). When E2 level was a continuous variable attempting to account for non-linear association, the relationship between survival endpoints and E2 was significantly nonlinear in pre-menopausal women. E2 levels were prognostic of OS in a J-shaped pattern (nonlinear $P=0.039)$; risk was flat to a threshold $(\sim 250 \mathrm{ng} / \mathrm{L})$, then increased gradually (Fig. 2A). E2 levels were prognostic of PFS in a U-shaped pattern (nonlinear $P=0.013$ ); risk was higher at the extreme (300 ng/L) but lower at intermediate values ( $>50$ to $<150 \mathrm{ng} / \mathrm{L})$ (Fig. 2B). The plot of the Fig. 2A and 2B showed a J-shaped and U-shaped relationship between log relative hazard and E2, indicating that lower or higher levels of E2 were associated with a higher hazard of death or progression, with the lowest risk of $128.7 \mathrm{ng} / \mathrm{L}$ and $103.3 \mathrm{ng} / \mathrm{L}$, respectively. When the E2 concentration was above $300 \mathrm{ng} / \mathrm{L}$, the risk of PFS gradually became flat, whereas OS was still elevated. As for post-menopausal women, there was a linear relationship, and the linearity $P$ values were 0.105 and 0.158 , respectively. The plot showed that the risk of death or progression increased gradually with increasing E2 concentration, both tending to be stable after 30ng/L (Fig. 2C and 2D).

\subsection{ER status of patients modified the prognostic effects of E2 levels on breast cancer survival}

When we analyzed the estrogen receptor status, both ER-positive and ER-negative demonstrated inconsistent fluctuation curves (Fig. 3). Patient ER status modified the prognostic association of E2 levels and OS or PFS in the pre-menopausal women. Among ER-positive patients, E2 levels were associated with OS or PFS in a linear pattern (linear OS: $P=0.568$; PFS: $P=0.412$ ), whereas among ER-negative patients, E2 levels were associated with OS or PFS in a U-shaped pattern (nonlinear OS: $P=0.0006$; PFS: $P=0.001$ ) (Fig. 3A and 3B). Compared with ER-negative patients, the risk of disease progression or death was higher in ER-positive breast cancer patients when E2 concentration was 100ng/L-300ng/L. In postmenopausal women, there was a positive linear correlation between E2 and death or progression in ERpositive and ER-negative breast cancer (Fig. 3C and 3D). ER status did not modify the prognostic association between E2 levels with OS or PFS in the post-menopausal women. Within $10 \mathrm{ng} / \mathrm{L}$, the progression or death risk for ER-positive was approximately the same as that for ER-negative. As for above 10ng/L, the risk for ER-positive was higher than ER-negative. 


\section{Discussion}

In this population-based cohort study of 8766 patients with breast cancer, E2 concentrations were prognostic of OS or PFS. In pre-menopausal women, the $J$ and $U$ shapes of these associations were generally nonlinear and modified by patients' ER status. Among ER-positive patients, lower E2 levels were associated with lower risk of death or progression, whereas among ER-negative patients, moderate levels of E2 were associated with lower risk of death or progression. Conversely, in post-menopausal women, the concentration of E2 was linearly proportional to death or progression and not modified by ER status.

In pre-menopausal women, there are few literatures about the relationship between E2 and breast cancer prognosis due to the inaccessibility of timed samples. As for the dose-response relationship between E2 and survival endpoints, Patients with an intermediate level of E2 had a better prognosis. Estrogens can bind to estrogen receptors and play a role in breast cancer progression[21]. It remains unclear how well circulating E2 levels cooperated with hormone receptor signaling in the breast. The evidence suggests that E2 levels in circulation are positively correlated with that in the breast tissue[22-24]. From previously published results, increased E2 may reduce the risk for breast-cancer specific mortality among participants with ER-negative tumors ( $\mathrm{HR}=0.16,95 \% \mathrm{Cl}$ : $0.05-0.63)$, but not among ER-positive tumors[12]. In our stratified analyses, ER-negative was U-shaped, while ER-positive increased linearly before menopause. The possible reason is that estrogen metabolites will cause cumulative genotoxic insult in ER-positive tumor[25]. In the absence of ER status breast cancer, low or excessive E2 levels could affect the function of the uterus or ovaries, thereby affecting the secretion of E2 or other hormones[26, 27], and indirectly affecting the prognosis of breast cancer. Micheli et al. have reported that high plasma testosterone strongly predicts poorer prognosis in breast cancer patients[28]. Low or high E2 concentration is just a marker of a general metabolic imbalance that provides a milieu in which cancer cell proliferation in the breast or another site is facilitated[29]. Further, compared with ER-negative, the risk of disease progression or death was higher in ER-positive breast cancer when E2 concentration was $100 \mathrm{ng} / \mathrm{L}-300 \mathrm{ng} / \mathrm{L}$, while there was an opposite relationship when it is less than $100 \mathrm{ng} / \mathrm{L}$ or greater than $300 \mathrm{ng} / \mathrm{L}$. The high expression of estrogen-responsive genes (PGR, GREB1, TFF1, and PDZK1) may be at a higher or lower level of E2, which affects the prognosis of breast cancer[30, 31].

In post-menopausal women, our finding that higher E2 levels were associated with moderately worse OS and PFS mirrors prior studies[12, 14, 32]. Lønning et al. reported that patients with higher estrogen levels had shorter time to progression[33]. However, in another study of 358 women diagnosed with stage I-IIIA breast cancer, E2 level in the higher 50th percentile was not associated with a higher risk of mortality (HR $=1.01,95 \% \mathrm{Cl}$ : $0.66-1.53)$ [13]. The reason for this result may be the modeling of E2 levels using categories[6]. As for the dose-response relationship between E2 and breast cancer prognosis, E2 levels had an increasing linear association with the prognosis of breast cancer and similar patterns in ERpositive and ER-negative patients. When the E2 concentration was above 20ng/L, ER-positive patients had a slightly higher risk of death or progression than ER-negative patients. Estrogens can bind to estrogen receptors and play a role in breast cancer progression[21, 34]. Preoperative E2 levels without hormone treatment degrade the prognosis of ER-positive patients compared with ER-negative patients. 
The possible reason for this result may be the data distribution. Most post-menopausal E2 concentrations are concentrated within $20 \mathrm{ng} / \mathrm{L}$, but there is still a lack of data for higher concentrations of E2 (only about 10\%), which may be associated with a better prognosis for ER-negative breast cancer when the concentration is high.

There are several strengths of this study. To the best of our knowledge, this is the first study to quantify the increased risk of all-cause mortality or disease progression for a specific E2 concentration among premenopausal breast cancer patients in China. In contrast to prior studies, our study models E2 levels as continuous variables using splines, which can contribute to keeping continuities in mortality risk between exposure concentration that enhances statistical power and is often easy to justify biologically and interpret clinically. The main strengths are the large sample size and hospital-based, timed sample, and high follow-up rates. The large sample size offers sufficient statistical power to evaluate the prognostic role of E2 levels by ER-specific subgroups. The use of clinically acquired preoperative E2 levels, coupled with menopausal status, makes the integration of clinico-pathological variables into dividing distinct risk profiles and offers the opportunity for personalized treatment.

Despite several strengths, there are several limitations. The number of patients with progression or death is small due to the generally good prognosis of breast cancer, even over an extended follow-up. Therefore, further multi-center prospective studies with longer-term follow-up will be needed to resolve these limitations. In addition, experimental studies to investigate the mechanism of the prognostic role of E2 in future studies are needed.

\section{Conclusions}

In summary, E2 levels were prognostic of all-cause mortality or progression in breast cancer, and the strength and shape of these prognostic associations varied in pre- menopausal and post-menopausal patients and were modified by ER status. Measurements of E2 levels can be used to accurately identify high-risk profiles, and predict patient outcomes clinically.

\section{Abbreviations}

BMl: Body mass index

Cl: Confidence intervals

E2: Estradiol

ER: Estrogen receptor

HER2: Human epidermal growth factor receptor-2

HIS: Hospital information system 
HR: Hazard ratios

IHC: Immunohistochemistry

OS: Overall survival

PFS: Progression-free survival

PR: Progesterone receptor

TBCCC: Tianjin Breast Cancer Cases Cohort

\section{Declarations}

\section{Ethics approval and consent to participate}

The investigators in TBCCC obtained informed consent from each breast cancer patient and participants or their guardians. The current study was in accordance with the ethical standards of the institutional research committee and with the 1964 Helsinki Declaration and its later amendments and it was approved by the research ethics board of the Tianjin Medical University Cancer Institute and Hospital.

\section{Consent for publication}

Not applicable.

\section{Availability of data and materials}

The datasets used and/or analysed during the current study are available from the corresponding author on reasonable request.

\section{Competing interests}

The authors declare that they have no competing interests.

\section{Funding}

This study was supported by the National Key Research and Development Program of China [Grant 2018YFC1315600], and National Natural Science Foundation of China [Grants 81974439, 81974488].

\section{Authors' contributions}

Junxian Li and Chenyang Li designed the study,did the statistical analysis and drafted the manuscript. Fengju Song reviewed and revised the manuscript. All authors made contribution to the establishment of TBCCC and approved the final version.

\section{Acknowledgements}


The authors thank all the staff members who participated in TBCCC and staffs working for the establishment of breast cancer clinical database.

\section{References}

1. Zhang S, Sun $\mathrm{K}$, Zheng R, Zeng H, Wang S, Chen R, Wei W, He J: Cancer incidence and mortality in China, 2015. Journal of the National Cancer Center 2021, 1(1):2-11.

2. Lei S, Zheng R, Zhang S, Chen R, Wang S, Sun K, Zeng H, Wei W, He J: Breast cancer incidence and mortality in women in China: temporal trends and projections to 2030. Cancer Biol Med 2021.

3. Sung H, Ferlay J, Siegel RL, Laversanne M, Soerjomataram I, Jemal A, Bray F: Global Cancer Statistics 2020: GLOBOCAN Estimates of Incidence and Mortality Worldwide for 36 Cancers in 185 Countries. CA Cancer J Clin 2021, 71(3):209-249.

4. Burstein HJ, Griggs JJ, Prestrud AA, Temin S: American society of clinical oncology clinical practice guideline update on adjuvant endocrine therapy for women with hormone receptor-positive breast cancer. J Oncol Pract 2010, 6(5):243-246.

5. Gruber CJ, Tschugguel W, Schneeberger C, Huber JC: Production and actions of estrogens. N Engl J Med 2002, 346(5):340-352.

6. Folkerd E, Dowsett M: Sex hormones and breast cancer risk and prognosis. Breast 2013, 22 Suppl 2:S38-43.

7. Hankinson SE, Manson JE, Spiegelman D, Willett WC, Longcope C, Speizer FE: Reproducibility of plasma hormone levels in postmenopausal women over a 2-3-year period. Cancer Epidemiol Biomarkers Prev 1995, 4(6):649-654.

8. Tamimi RM, Byrne C, Colditz GA, Hankinson SE: Endogenous hormone levels, mammographic density, and subsequent risk of breast cancer in postmenopausal women. J Natl Cancer Inst 2007, 99(15):1178-1187.

9. Eliassen AH, Missmer SA, Tworoger SS, Spiegelman D, Barbieri RL, Dowsett M, Hankinson SE: Endogenous steroid hormone concentrations and risk of breast cancer among premenopausal women. $J$ Natl Cancer Inst 2006, 98(19):1406-1415.

10. Kaaks R, Berrino F, Key T, Rinaldi S, Dossus L, Biessy C, Secreto G, Amiano P, Bingham S, Boeing $\mathrm{H}$ et al: Serum sex steroids in premenopausal women and breast cancer risk within the European Prospective Investigation into Cancer and Nutrition (EPIC). J Natl Cancer Inst 2005, 97(10):755-765.

11. Key T, Appleby P, Barnes I, Reeves G, Endogenous H, Breast Cancer Collaborative G: Endogenous sex hormones and breast cancer in postmenopausal women: reanalysis of nine prospective studies. $J$ Natl Cancer Inst 2002, 94(8):606-616. 
12. Kensler KH, Eliassen AH, Rosner BA, Hankinson SE, Brown M, Tamimi RM: Prediagnostic sex hormone levels and survival among breast cancer patients. Breast Cancer Res Treat 2019, 174(3):749758.

13. Duggan C, Stanczyk F, Campbell K, Neuhouser ML, Baumgartner RN, Baumgartner KB, Bernstein L, Ballard R, McTiernan A: Associations of sex steroid hormones with mortality in women with breast cancer. Breast Cancer Res Treat 2016, 155(3):559-567.

14. Kim JY, Han W, Moon HG, Ahn SK, Kim J, Lee JW, Kim MK, Kim T, Noh DY: Prognostic effect of preoperative serum estradiol level in postmenopausal breast cancer. BMC Cancer 2013, 13:503.

15. Li J, Liu L, Feng Z, Wang X, Huang Y, Dai H, Zhang L, Song F, Wang D, Zhang P et al: Tumor markers CA15-3, CA125, CEA and breast cancer survival by molecular subtype: a cohort study. Breast Cancer 2020, 27(4):621-630.

16. Zhang L, Huang Y, Feng Z, Wang X, Li H, Song F, Liu L, Li J, Zheng H, Wang P et al: Comparison of breast cancer risk factors among molecular subtypes: A case-only study. Cancer Med 2019, 8(4):18821892.

17. Untch M, Gerber B, Harbeck N, Jackisch C, Marschner N, Mobus V, von Minckwitz G, Loibl S, Beckmann MW, Blohmer JU et al: 13th st. Gallen international breast cancer conference 2013: primary therapy of early breast cancer evidence, controversies, consensus - opinion of a german team of experts (zurich 2013). Breast Care (Basel) 2013, 8(3):221-229.

18. Farhat GN, Cummings SR, Chlebowski RT, Parimi N, Cauley JA, Rohan TE, Huang AJ, Vitolins M, Hubbell FA, Manson JE et al: Sex hormone levels and risks of estrogen receptor-negative and estrogen receptor-positive breast cancers. J Nat/ Cancer Inst 2011, 103(7):562-570.

19. Meira-Machado L, Cadarso-Suarez C, Gude F, Araujo A: smoothHR: an R package for pointwise nonparametric estimation of hazard ratio curves of continuous predictors. Comput Math Methods Med 2013, 2013:745742.

20. Harrell F: Regression Modeling Strategies: With Applications to Linear Models, Logistic and Ordinal Regression, and Survival Analysis. New York City, NY: Springer; 2015.

21. Clark GM, Osborne CK, McGuire WL: Correlations between estrogen receptor, progesterone receptor, and patient characteristics in human breast cancer. J Clin Oncol 1984, 2(10):1102-1109.

22. Lonning PE, Helle H, Duong NK, Ekse D, Aas T, Geisler J: Tissue estradiol is selectively elevated in receptor positive breast cancers while tumour estrone is reduced independent of receptor status. $J$ Steroid Biochem Mol Biol 2009, 117(1-3):31-41.

23. Vermeulen A, Deslypere JP, Paridaens R, Leclercq G, Roy F, Heuson JC: Aromatase, 17 betahydroxysteroid dehydrogenase and intratissular sex hormone concentrations in cancerous and normal 
glandular breast tissue in postmenopausal women. Eur J Cancer Clin Oncol 1986, 22(4):515-525.

24. Bonney RC, Reed MJ, Davidson K, Beranek PA, James VH: The relationship between 17 betahydroxysteroid dehydrogenase activity and oestrogen concentrations in human breast tumours and in normal breast tissue. Clin Endocrinol (Oxf) 1983, 19(6):727-739.

25. Germain D: Estrogen carcinogenesis in breast cancer. Endocrinol Metab Clin North Am 2011, 40(3):473-484, vii.

26. Missmer SA, Eliassen AH, Barbieri RL, Hankinson SE: Endogenous estrogen, androgen, and progesterone concentrations and breast cancer risk among postmenopausal women. $J$ Natl Cancer Inst 2004, 96(24):1856-1865.

27. Cummings SR, Lee JS, Lui LY, Stone K, Ljung BM, Cauleys JA: Sex hormones, risk factors, and risk of estrogen receptor-positive breast cancer in older women: a long-term prospective study. Cancer Epidemiol Biomarkers Prev 2005, 14(5):1047-1051.

28. Micheli A, Meneghini E, Secreto G, Berrino F, Venturelli E, Cavalleri A, Camerini T, Di Mauro MG, Cavadini E, De Palo G et al: Plasma testosterone and prognosis of postmenopausal breast cancer patients. J Clin Oncol 2007, 25(19):2685-2690.

29. Pasanisi P, Berrino F, De Petris M, Venturelli E, Mastroianni A, Panico S: Metabolic syndrome as a prognostic factor for breast cancer recurrences. Int J Cancer 2006, 119(1):236-238.

30. Haynes BP, Viale G, Galimberti V, Rotmensz N, Gibelli B, A'Hern R, Smith IE, Dowsett M: Expression of key oestrogen-regulated genes differs substantially across the menstrual cycle in oestrogen receptorpositive primary breast cancer. Breast Cancer Res Treat 2013, 138(1):157-165.

31. Dunbier AK, Anderson H, Ghazoui Z, Folkerd EJ, A'Hern R, Crowder RJ, Hoog J, Smith IE, Osin P, Nerurkar $A$ et al: Relationship between plasma estradiol levels and estrogen-responsive gene expression in estrogen receptor-positive breast cancer in postmenopausal women. J Clin Oncol 2010, 28(7):11611167.

32. Rock CL, Flatt SW, Laughlin GA, Gold EB, Thomson CA, Natarajan L, Jones LA, Caan BJ, Stefanick $\mathrm{ML}$, Hajek RA et al: Reproductive steroid hormones and recurrence-free survival in women with a history of breast cancer. Cancer Epidemiol Biomarkers Prev 2008, 17(3):614-620.

33. Lonning PE, Helle SI, Johannessen DC, Ekse D, Adlercreutz H: Influence of plasma estrogen levels on the length of the disease-free interval in postmenopausal women with breast cancer. Breast Cancer Res Treat 1996, 39(3):335-341.

34. Folkerd EJ, Dowsett M: Influence of sex hormones on cancer progression. J Clin Oncol 2010, 28(26):4038-4044. 


\section{Figures}

A.

Premenopause

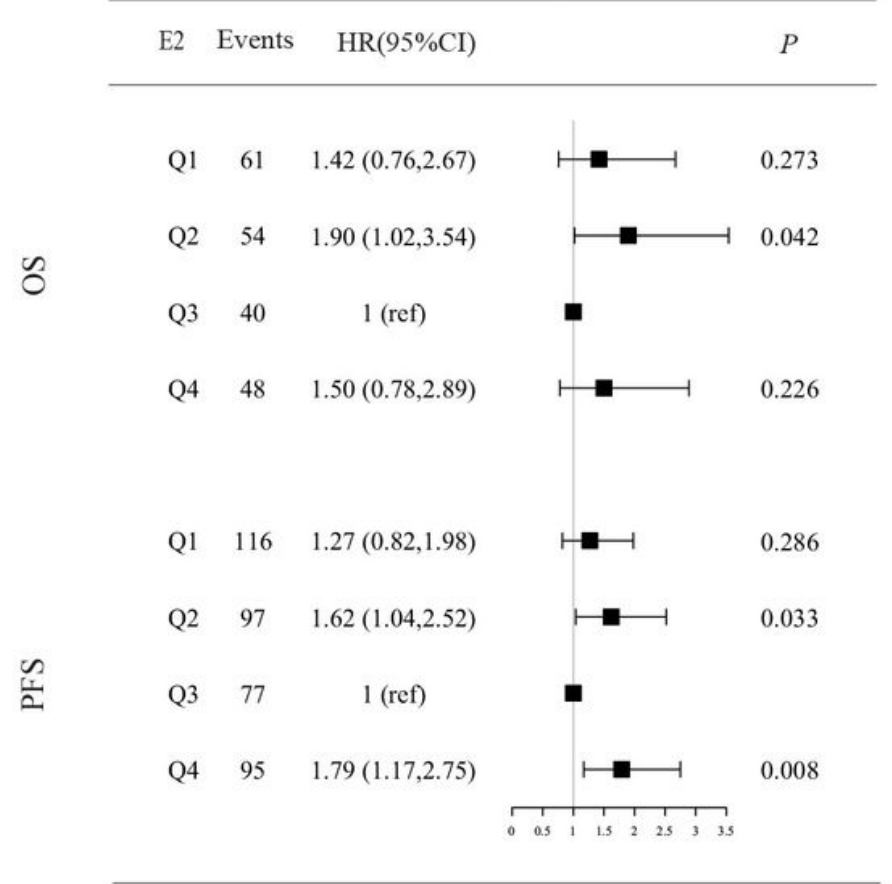

B.

Postmenopause

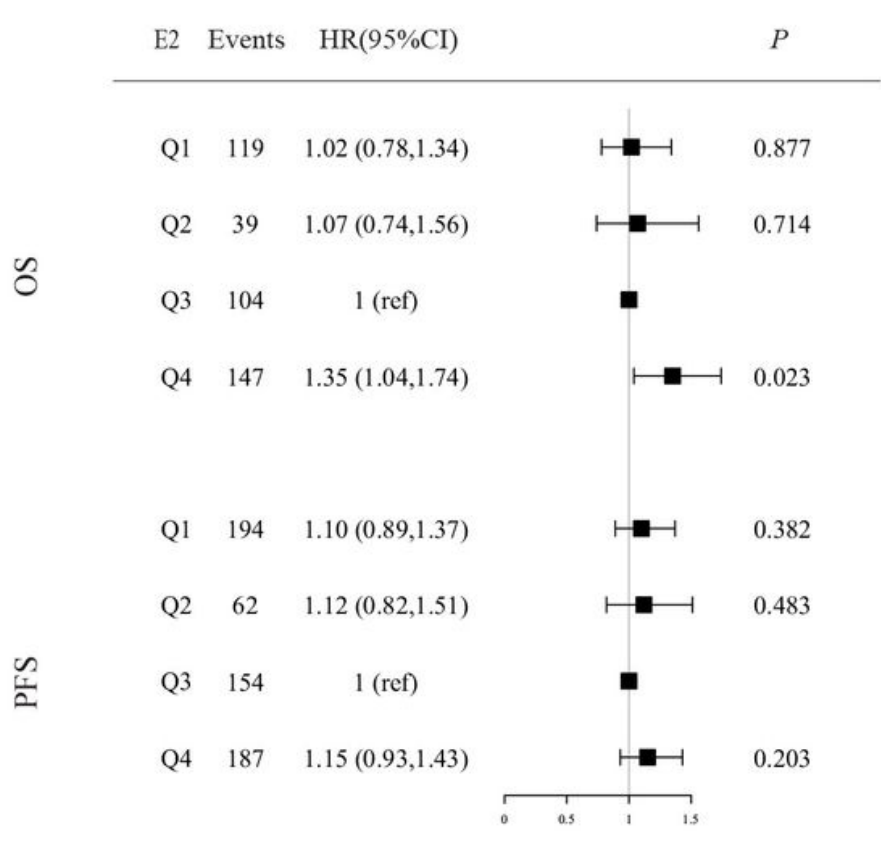

\section{Figure 1}

Multivariate Cox regression analysis for E2 and OS or PFS by Menopausal status . A : Pre-menopause; Adjusted for age at diagnosis, BMI, pT, pN, stage, histological grade, ER, PR, HER2 status, chemotherapy, radiotherapy, endocrine treatment. B: Post-menopause; Adjusted for age at diagnosis, BMI, pT, pN, chemotherapy, radiotherapy, endocrine treatment. Abbreviations: $\mathrm{HR}$, hazard ratio; $\mathrm{Cl}$, confidence interval; $\mathrm{BMI}$, body mass index; ER, estrogen receptor; PR, progesterone receptor; HER2, human epidermal growth factor receptor-2. 
A.

Premenopause

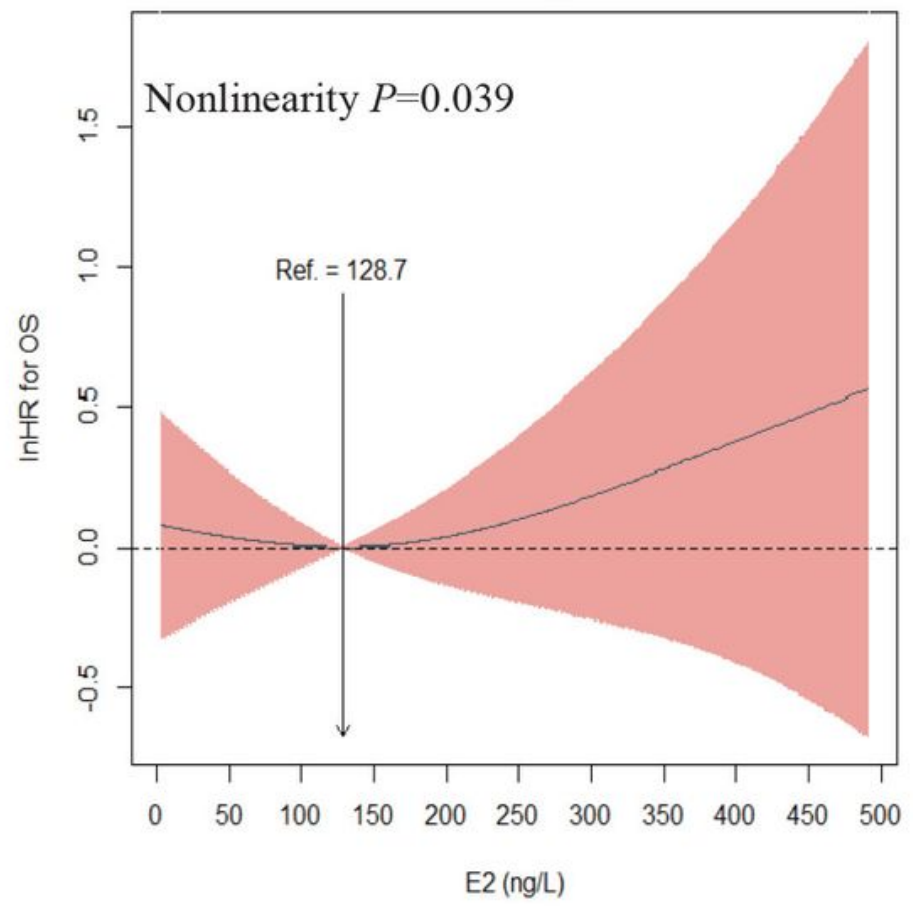

B.

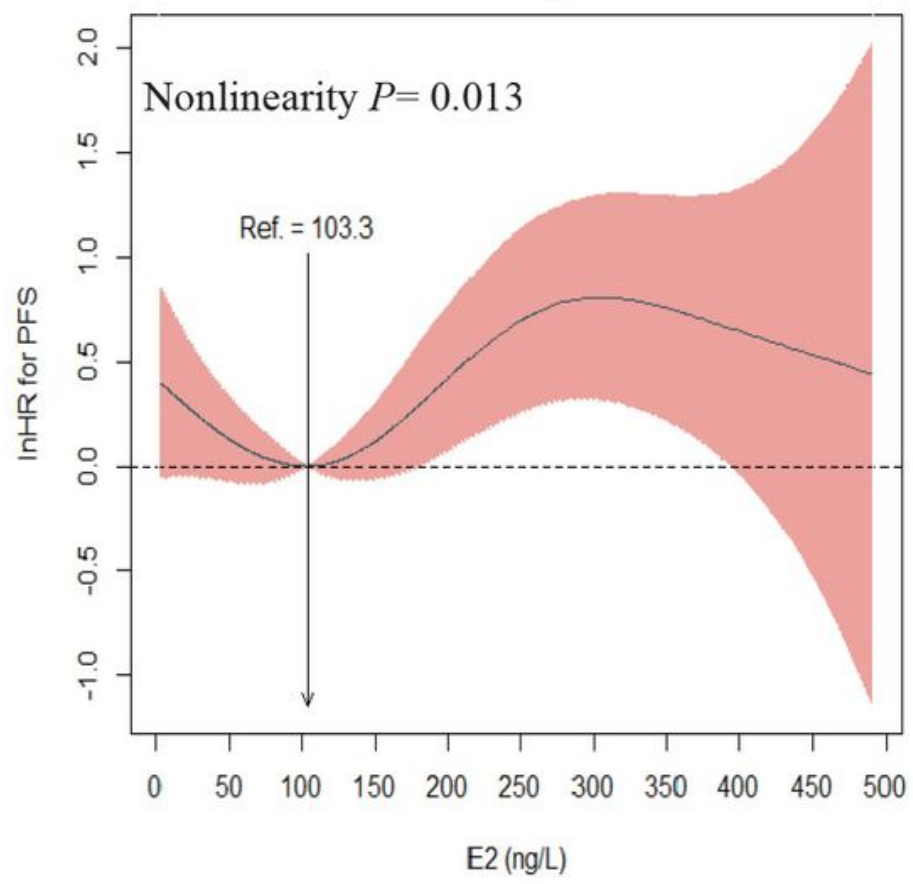

C. Postmenopause
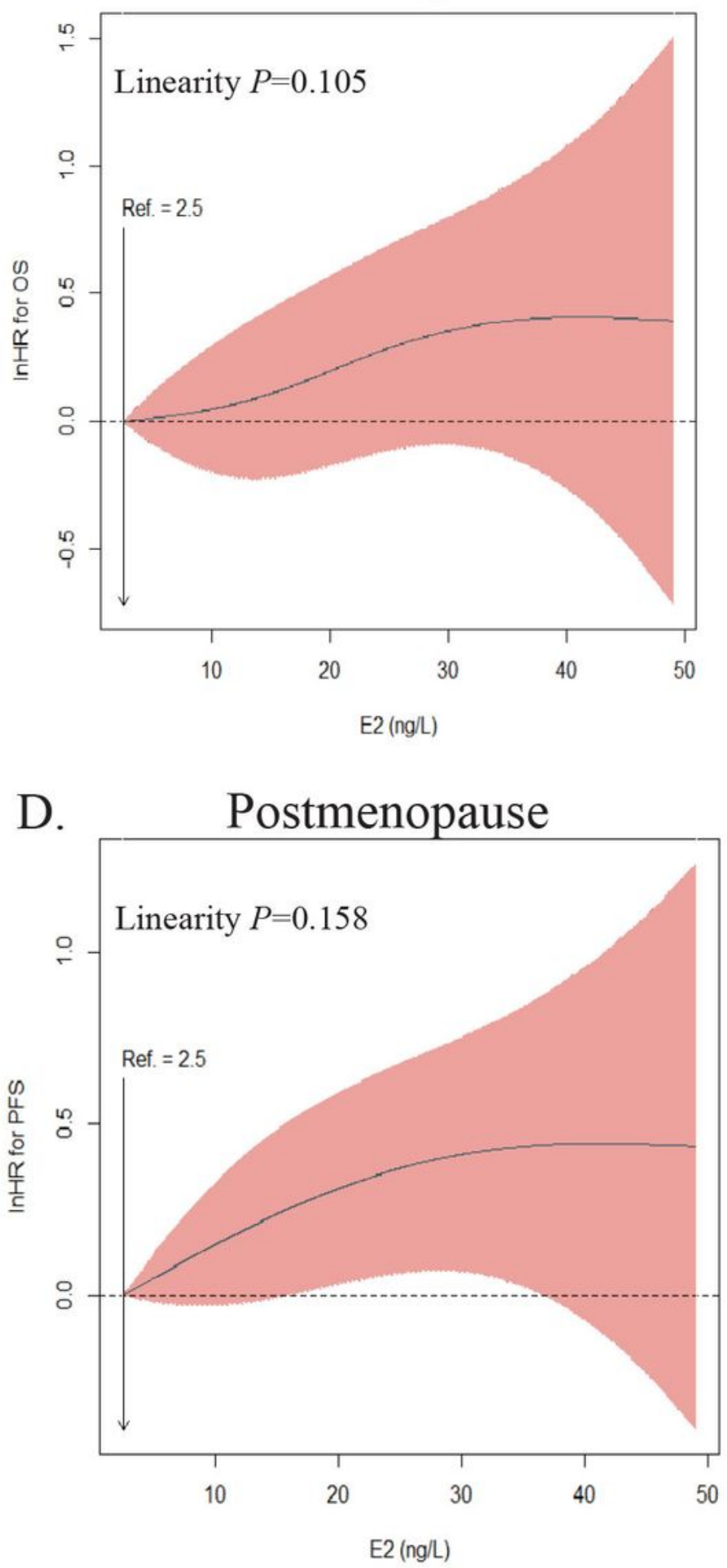

\section{Figure 2}

E2 on a continuous scale and the risk of outcomes in pre- and post-menopausal patients. Estimated logarithm hazard ratios (HRs) (solid lines) with 95\% confidence intervals (shading) for the association of E2 in blacks with overall survival (OS) or progression free survival (PFS) in pre-menopausal (A and B); and post-menopausal ( $C$ and $D$ ) patients based on the dfmacox in a smoothHR - the optimal extended Cox-type additive hazard regression adjusted model. The effects of E2 on the risk of recurrence, 
metastasis, and mortality are modeled with a penalized spline (P-spline) expansion, with E2 concentration as a continuous covariate. The vertical lines are used as the reference value for calculating the HRs. Abbreviations: OS, Overall Survival; PFS, Progression Free Survival.
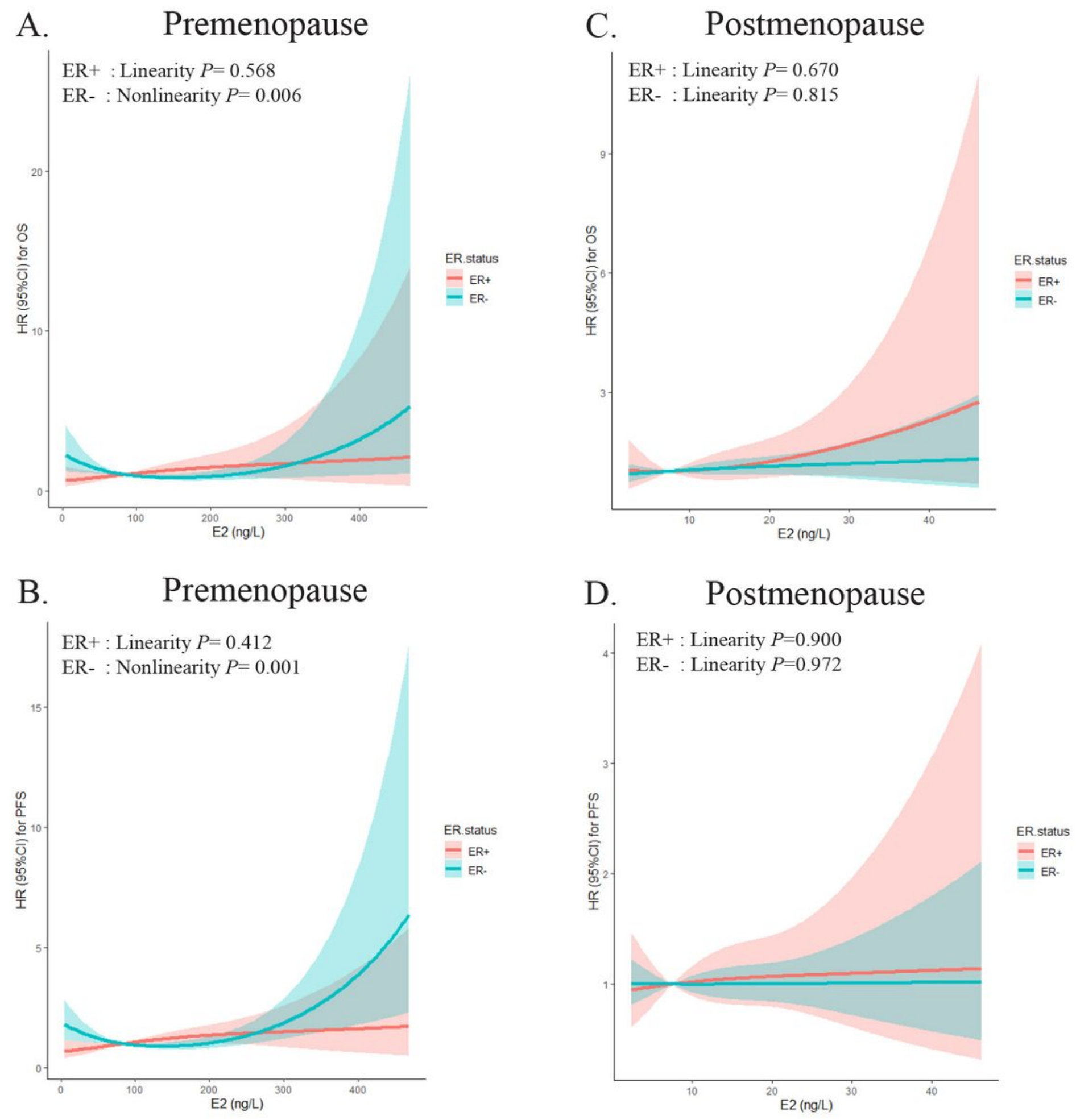

\section{Figure 3}

E2 on a continuous scale and the risk of outcomes stratified by ER status. A and B: pre-menopausal breast cancer patients $C$ and $D$ : post-menopausal breast cancer patients Abbreviations: ER, estrogen 
receptor; OS, Overall Survival; PFS, Progression Free Survival. 